\title{
What Really Matters in Locating Shared Humanitarian Stockpiles: Evidence from the WASH Cluster
}

\author{
Sander de Leeuw ${ }^{1}$, Laura Rock Kopczak ${ }^{2}$, and Martijn Blansjaar ${ }^{3}$ \\ ${ }^{1}$ VU University Amsterdam, Faculty of Economics \& Business Administration, \\ De Boelelaan 1105, 1081 HV Amsterdam, Netherlands \\ sleeuwa feweb.vu.nl \\ ${ }^{2}$ Zaragoza Logistics Center, Edificio Náyade 5, C/Bari 55 - PLAZA, 50197 Zaragoza, Spain \\ kopczak@stanfordalumni.org \\ ${ }^{3}$ Oxfam GB, Oxfam House, John Smith Drive, Cowley, Oxford OX4 2JY, UK \\ MBlansjaar@Oxfam.org.uk
}

\begin{abstract}
Through a case study of locating shared stockpiles at the United Nations Water Sanitation and Health (WASH) cluster, we contribute to literature by characterizing the real overriding complexities that impact location of shared humanitarian stockpiles. We find that unique complexities related to 1) demand patterns/projections, 2) charter and commercial transport rate structures and uncertainties, 3) interagency supply and dispatch networks, 4) how programs and donors define service requirements and provide direction, and 5) in-kind service donations, all come into play and materially affect the analysis. We recommend that further research be done in these areas.
\end{abstract}

Keywords: collaboration, humanitarian logistics, supply chain design.

\section{Introduction}

It is generally understood that stockpiling items is necessary to provide timely and cost effective response to disasters [1]. Locating these stockpiles in humanitarian supply chains is receiving increasing attention, particularly in the OR domain [2-4]. Typically, several aspects encountered in practice are not modeled. For example, no model accounts for response tactics of organisations. Some organisations may only provide specialised activities that are not always necessary (e.g. search and rescue) whereas others provide broad cover. Context influences response tactics; few response models for rural areas are transferable to urban settings. Needs vary by disaster type [5]: disasters always require a form of water supply to people in need but earthquakes necessitate trucking of water as the water piping system will be deteriorated; if local water supply is still operational, water purification equipment may suffice. Supply aspects are furthermore not taken into account explicitly; stockpile strategies differ dependent on local or global sourcing of supplies. Last, models all take the perspective of one organisation.

Under the umbrella of the clusters formed by the United Nations in 2005 , organisations have started to cooperate in responding to disasters. Through a case 
study of locating shared stockpiles at the United Nations Water Sanitation and Health (WASH) cluster we contribute to literature by eliciting and characterizing the real overriding complexities that impact location of shared humanitarian stockpiles.

\section{The WASH Stockpile Project ${ }^{1}$}

In 2005, the UN established nine (later eleven) collaborative platforms of humanitarian activity (referred to as "clusters") ${ }^{2}$ to address the problem of coordination among agencies. One of these clusters is the Water Sanitation and Hygiene (WASH) cluster, for which UNICEF has been appointed as lead agency and a global cluster working group created ${ }^{3}$. Water is one of the dearest items after disaster strikes and crucial to survival. Availability of WASH materials and equipment is essential to any humanitarian response. Yet, for beneficiaries access to water and provision of sanitation in the aftermath of a disaster is often problematic.

WASH materials and equipment can be divided into 6 categories based on intended use, of which three - water treatment, trucking and storage \& distribution make use of water related materials and equipment (e.g. bladder tanks, pipes, tanks, pumps and water purification items). The other are sanitation (e.g. latrine slabs, potties), hygiene (e.g. hygiene kits or soap) and "other" (e.g. reference books). The WASH stockpile project is one of several WASH cluster projects that are being pursued to support the cluster objective of having greater preparedness within the sector for response to emergencies. Phase I concluded that timely availability of appropriate WASH related materials and equipment on the ground after an emergency was limited in some cases because agencies with capacity on the ground did not have materials. To address this gap, Phase I recommended a comprehensive programmatic solution consisting of a shared stockpile of WASH items that would:

- Stock and deploy a pre-defined standardized set of WASH materials organized in six modules with quantities to support 50,000 beneficiaries and response capability to address a single large emergency $(50,000)$ or multiple smaller emergencies; and

- Be deployed by the WASH cluster and delivered within one week after activation of the WASH cluster to one or more implementing agencies in country that have capacity on the ground to respond.

- Be in addition to existing agency stocks.

- Be pre-funded for multiple years including cost of dispatch and stock replenishment after use.

\footnotetext{
${ }^{1}$ This is project 5 of the WASH cluster. Project documents for Phase I and Phase II of this project can be found on http://www.humanitarianreform.org/Default.aspx?tabid=345

2 The other clusters are agriculture, camp coordination and management, early recovery, education, emergency shelter, emergency telecom, health, logistics, nutrition, and protection.

${ }^{3}$ Current active members of the working group include: Action Contre la Faim (ACF), CARE, Center for Disease Control (CDC), Concern, Catholic Relief Services (CRS), InterAction, International Center for Health and Migration (ICHM), International Federation of Red Cross and Red Crescent Societies (IFRC), International Rescue Committee (IRC), MercyCorps, Norwegian Church Aid (NCA), Oxfam, REDR-IHE, TearFund, UNHCR, UNRWA, WHO and World Vision International (WVI).
} 


\subsection{Project Approach for Phase II}

This paper focuses on Phase II of the project, which was managed by Martijn Blansjaar of Oxfam GB with the two other authors acting as consultants to develop the solution. Phase II investigated the design of the supply chain and selection of supply chain partners together, acknowledging that different sets of partners would offer different supply chain options with different potential for performance. Furthermore, the project sought to make maximum use of existing agency capacity in designing supply chain options, thereby minimising set-up and operating expenditure and delay. The WASH cluster thus focused on the logistics departments of WASH cluster member agencies as potential partners; eight agencies that had expressed interest in participating were considered. Logistics service providers were considered only to the extent that the agencies being considered were using them. The intent was to select agencies and design a collaborative supply chain to be implemented once funding was obtained in a two-year pilot, after which an evaluation and potential adjustment would be made.

The project ran from August to December 2009. During that time, the consultants developed supply chain alternatives, evaluation criteria and interview scripts which were then agreed upon by the steering committee (a sub-section of the working group). Based on initial agency interviews with the eight agencies, a short list of four supply chain alternatives with participating agencies was decided upon. The predefined evaluation criteria were used twice - once to narrow the list of agencies/supply chains and a second time to compare the short-listed options.

A demand and stock location/allocation analysis was conducted in parallel with agency interviews and site visits. A workshop was held in Geneva in late September 2009 to solicit agency input. Site visits were made to the procurement/supply chain department offices of the short listed agencies in Bicester (UK), Geneva, and Oslo, to UNICEF (the cluster lead) in Copenhagen, and to dispatch warehouses in Bicester (UK), Kuala Lumpur and Dubai. Design reviews were conducted to understand overlap of current materials and suppliers with WASH stockpile items. Finally, recommendations were presented to and agreed upon by the steering group.

\subsection{Analyzing Potential Stockpile Locations for a Given Set of Agencies}

WASH Cluster members discussed and agreed on items and related specifications and packaging for six modules as described in section 2 above, with the intent that the six modules would be deployed together for a comprehensive solution in sets to fulfill needs of 5,000 beneficiaries, with a minimum deployment quantity for 10,000 and a maximum deployment for 50,000 beneficiaries. It was estimated that a set of the six modules to support 10,000 beneficiaries would cost roughly USD $\$ 200,000$, weigh 28,000 kilograms and occupy roughly 150 cubic meters. This load could fit well in the commonly used IL76 rear loading charter aircraft or similar.

Four alternative supply chain concepts with varying agency participation were analyzed using a spreadsheet. The analysis looked at (among other things) transport costs for different stockpile locations, stock allocation, and transport options, for a given demand scenario. The recommended supply chain was the Oxfam-IFRC supply chain with additional potential to leverage UNICEF transport contracts and ability to 
receive goods in country (as a diplomatic entity). The analysis was based on the related supply chain design and considered existing locations and current transport approaches of the three agencies as shown in the table below. Using current processes will ease implementation of the pilot. Interested readers are referred to the project documents mentioned above in footnote 1 .

Table 1. Supply chain design

\begin{tabular}{lll}
\hline $\begin{array}{l}\text { Anticipated location of } \\
\text { source of supply }\end{array}$ & $\begin{array}{l}\text { Existing dispatch warehouse } \\
\text { locations }\end{array}$ & Current transport approaches \\
\hline $\begin{array}{l}\text { Water modules: complete } \\
\text { modules from UK suppliers } \\
\text { through Oxfam }\end{array}$ & $\begin{array}{l}\text { IFRC: Dubai, Kuala } \\
\text { Lumpur, Panama City, Gran } \\
\text { Canarias }\end{array}$ & $\begin{array}{l}\text { IFRC: Charter/scheduled air } \\
\text { cargo, ocean depending on } \\
\text { origin-destination pair }\end{array}$ \\
$\begin{array}{l}\text { Oxfam: Bicester } \\
\text { reference modules: from }\end{array}$ & UNICEF: Copenhagen, & $\begin{array}{l}\text { Oxfam: Commercial air } \\
\text { Usian or regional suppliers }\end{array}$ \\
Dubai & & $\begin{array}{l}\text { commercial air depending on } \\
\text { origin-destination pair }\end{array}$ \\
\hline
\end{tabular}

\subsection{Findings from Demand Analysis and Service Requirements Workshop}

A demand analysis was done in an effort to better project the location, timing and size of needs that will potentially be addressed by dispatching from the stockpile. With help from Oxfam GB WASH engineers, we analysed publicly available data on flash appeals to determine for which of these past emergencies WASH modules would have been deployed and in what quantities. ${ }^{4}$ It was determined that if a stockpile had been in place, modules would have been deployed for 17 of the 50 flash appeals during that time. ${ }^{5}$ The resulting annual demand scenario is shown below:

- 1 big emergency (deployment of modules to support 50,000 people)

$>$ Location: $50 \%$ chance in Africa and $50 \%$ in Asia

$>$ Timing: May hit anytime throughout the year

- 3-4 small/medium emergencies (total deployment to support 45,000 people)

> Location: 2 in Africa, 1 in Asia, 1.5 in Latin America

$>$ Timing: Roughly $75 \%$ of this demand would occur during the peak season (July-December).

This analysis is limited by the fact that data on flash appeals only covers the years 2005-2009. It appeared from this limited data set that if a large emergency occurs

\footnotetext{
4 "A Flash Appeal is the way that the many agencies responding to a sudden humanitarian crisis coordinate their response and present a unified set of needs to donors. It provides a concise overview of urgent life-saving needs and a plan to address acute needs for up to six months based on the best available information at the time of writing. A Flash Appeal may be developed into a Consolidated Appeal if the emergency continues beyond six months. All implementing agencies, ranging from UN agencies, international organisations, the Red Cross Movement, and NGOs, are encouraged to list their humanitarian projects in a joint Appeal." http://ocha.unog.ch/ets/Default.aspx?ContentType=FixedContent\&ContentID=3.

${ }^{5}$ The hygiene promotion kit (printed materials) alone would have been deployed for an additional 6 of the 50 flash appeals.
} 
(or two in a year, as with the tsunami and Pakistan earthquake), agencies might respond to fewer or no small to medium-size emergencies that year. We chose not to reflect this as an either/or situation in the demand scenario. From the flash appeal data (and discussions with WASH experts) we concluded that Latin America is typically hit by disasters requiring a small response (for 10,000 beneficiaries); nevertheless in early 2010 Haiti was hit by an earthquake that would be considered a big emergency.

In the September 2009 workshop, consultants led a discussion among WASH engineers and logisticians that defined a service requirement for dispatch speed (dispatch warehouse to receipt in country) of 48 hours to 7 days and a service requirement for replenishment time (stock dispatched to stock received) of 60 days.

\subsection{Findings from Analysis of Stockpile Location/Allocation}

In keeping with the collaborative approach to the stockpile and the idea of leveraging existing agency capacity, we used existing response approaches and networks of individual agencies as a starting point. Using a spreadsheet we analysed where to hold stock and how to allocate the 50,000 unit stockpile and a possible 10,000 additional units during peak season among potential locations (Dubai, Kuala Lumpur, Panama City, Las Palmas, Bicester) to respond to the demand scenario. All locations have good access to airports and flight times are less than 12 hours different.

The analysis approach taken was to obtain indicative charter airfares from UNICEF and IFRC for transport from warehouses indicated to sample destinations represented in our demand analysis. ${ }^{6}$ In analyzing each stockpile option, we used the indicative transport rates to decide from which stockpile location each destination would be served. We then calculated a projected annual transport cost for the demand scenario, weighing the cost of responding to large and small emergencies equally.

We found that looking solely at charter air transport cost led to a narrow analysis, with few factors considered. Even so, while some insights were gained, the results were inconclusive because the indicative transport rates obtained from the multiple agencies varied so dramatically that the order of preference of stockpile locations and the value of holding additional 10,000 units of stock during the peak season changed dependent on whether UNICEF or IFRC transport rates were used. UNICEF rates were relatively more favorable for "northern" origins such as Bicester; IFRC rates were relatively more favorable for IFRC regional hub locations in KL and Panama City. ${ }^{7}$ Indicative charter transport costs for an IL76 charter are roughly equal to the item cost for a quantity of 10,000 but potentially 2 to 3 times that cost on particular origin-destination pairs. We also found that charter air rates for some lanes (e.g. Panama City to African destinations) were asymmetric due to unbalanced flows. What we could conclude from the analysis was that a single location strategy is very expensive for serving small disasters in the regions - apart from the question of whether it is a good idea to do so - and that keeping a significant amount of stock in Europe and in Panama City would be very expensive because large disasters are not very likely to occur there. (In contrast, one stockpile in Dubai would serve large disasters well because it is well positioned for both Africa and Asia.) To carry

\footnotetext{
${ }^{6}$ Pakistan, Haiti, Zimbabwe, Philippines, Burkina Faso, Uganda, Mozambique.

${ }^{7}$ This could be due, for example, to relative volumes for the two agencies on particular lanes or focus of their freight forwarders with respect to lanes.
} 
forward this narrow analysis, we would have to work further to understand the differences in UNICEF and IFRC rates.

Additional factors that would come into play in a broader analysis include:

- A solution in which, for example, some stock is held by Oxfam in Bicester and some by IFRC in Dubai and Panama City, seems attractive, particularly as Oxfam engineers would have stock close by that could be examined should engineering issues arise. However, physical, financial and information processes would be more complex and deciding from which stockpile to deploy (commercial from Bicester vs. commercial/charter from elsewhere) could become an issue.

- Some donors may prefer to see stock in particular locations or held by particular agencies.

- Variability in charter air rates / plane availability over time is not well understood.

- Possibilities for use of scheduled commercial flights and for donated space on these flights should be investigated further. A quick look suggested that scheduled cargo rates may be as low as one tenth of charter rates, but require a trade-off between cost and response time that would have to be made by WASH cluster programs. Donated space occurs typically as ad hoc offers for flights from "northern" origins.

\section{Discussion}

Three major aspects made it difficult to develop a conclusive design. First, it is necessary to understand the demand and desired response to a disaster. Understanding the demand side was not seen as a necessary first step by the agencies involved. It is fairly typical for the current humanitarian supply chain literature to state that demand is "...unpredictable regarding timing, location and scale" [6] without further detailed analysis. Our analysis - though not complete and in need of further work - shows that natural disaster occurrence is not that unpredictable as typically understood. Discussions with programs on required responsiveness in the supply chain were inconclusive: trading off speed in delivery with costs of that delivery (including costs of capacity on the ground to set up the operation) was not seen as an input to design; instead, programs just set response times irrespective of potential cost impact.

The input to the project was a requested stock level to serve 50,000 beneficiaries. Such a requirement may be a simple statement used for a donor but in reality it is unclear what it implies. Does this mean that stock for 50,000 people is required at all times? If so, peak stock levels (order-up-to points) may need to be higher. Discussions about this with the programs were inconclusive.

Our results are inconclusive because of uncertainty in transport costs. Transport costs are asymmetric along lanes and are influenced by aircraft availability and choice for chartered vs. commercial air cargo. It is clear that inclusion of transport cost in any location analysis is crucial due to the level of costs, unlike e.g. Duran et al. [3] who do not take operating costs into account. Research - including ours - often assumes that aircraft is the typical mode of response for disasters but that is not the only option for response, c.f. Pettit and Beresford [1]. Response by truck or ship may be equally well possible. Also, we found that an apparently growing volume of governments and corporations offer of in-kind service support (e.g. free warehouse space in the Humanitarian City in Dubai, free air-cargo transport offered by scheduled 
freight carriers) can potentially reduce operating costs, but may increase coordination needs or limit flexibility.

Last, the set up of a shared stockpile poses several challenges that interact with the outcome of a location analysis. The preferred scenarios seemed to be influenced by respective transport rate tables. Therefore, one needs to decide who will do the contracting and whose transport rates will be used. This is not a matter of simply selecting the cheapest overall due to the fact that both quotes showed different preferred scenarios though total lowest costs were roughly similar. This implies one needs to think of a transport strategy first: will we rely on chartered aircraft for response or will we also use commercial air? Discussions with donors also showed that they sometimes have preferences that influence the design; donors may make their funding dependent on the use of certain locations or suppliers.

\section{Conclusion and Future Research}

In this article we have identified the real complexities and practical challenges that humanitarian agencies face when designing a shared stockpile. Additional research is needed to understand and characterise demand as input for location analysis, to incorporate transport rate complexity and uncertainty, to investigate the size and impact of in-kind service donations, to investigate interagency coordination problems, particularly in the area of contracting, and to research the role of programmes and donors in providing directives for the humanitarian supply chain.

\section{References}

1. Pettit, S., Beresford, A.: Critical success factors in the context of humanitarian aid supply chains. Int. J. Phys. Distrib. 39(6), 450-468 (2009)

2. Balcik, B., Beamon, B.: Facility location in humanitarian relief. Facility location in humanitarian relief 11(2), 101-121 (2008)

3. Duran, S., Gutierrez, M.A., Keskinocak, P.: Pre-Positioning of Emergency Items Worldwide for CARE International. In: INFORMS, USA (2007)

4. Rawls, C.G., Turnquist, M.A.: Pre-positioning of emergency supplies for disaster response. Transp. Res. B 44, 521-534 (2010)

5. Tomasini, R.M., Van Wassenhove, L.N.: From preparedness to partnerships: case study research on humanitarian logistics. Int. Trans. Oper. Res. 16(5), 549-559 (2009)

6. Kovacs, G., Spens, K.M.: Humanitarian logistics in disaster relief operations. Int. J. Phys. Distrib. 37(2), 99-114 (2007) 